\section{OAK RIDGE \\ NATIONAL LABORATORY}

MANAGED BY UT-BATTELLE

FOR THE DEPARTMENT OF ENERGY
ORNL-00-0609

Energy and Transportation Science Division

Final Report for

CRADA Number ORNL-00-0609

\title{
Real-Time Control of Diesel Combustion Quality
}

Robert M. Wagner

Oak Ridge National Laboratory

Kevin Sisken

Detroit Diesel Corporation

APPROVED FOR PUBLIC RELEASE

Prepared by Oak Ridge National Laboratory Oak Ridge, TN 37831

Managed by UT-BATTELLE, LLC for the U.S. Department of Energy บT-BATTELLE 


\section{Abstract}

Detroit Diesel Corporation (DDC) and ORNL established this CRADA to improve heavy-duty engine efficiency with reduced emissions at relatively extreme operating regimes such has high EGR, low-load, and cold-start, with an emphasis on the application of advanced control strategies. The approach used in this collaborative effort was to include the application of novel analysis and modeling techniques developed from the application of nonlinear dynamics and chaos theory. More specifically, analytical techniques derived from these theories were to used to detect, characterize, and control the combustion instabilities that are responsible for poor combustion performance and corresponding high emissions.

The foundation of this CRADA was established based on ORNL expertise on the fundamentals of advanced combustion operation and experience with nonlinear dynamics and controls in combustion systems. The initial plan was all data generation would be performed at DDC with an agreed upon experimental plan formed by both organizations. While numerous experiments were performed at DDC and the data was exchanged with ORNL researchers, the team decided to transfer an engine to ORNL to allow more flexibility and data generation opportunities. A prototype DDC Series 60 with a common rail fuel system was selected and installed at ORNL.

DDC and ORNL maintained a strong collaboration throughout much of this project. Direct funding from DOE ended in 2004 and DDC continued to fund at a reduced amount through 2007. This CRADA has not been funded in more recent years but has been maintained active in anticipation of restored funding. This CRADA has led to additional collaborations between DDC and ORNL.

\section{Statement of Objectives}

- Explore and establish boundaries of high efficiency clean combustion (HECC) modes on a DDC heavy-duty diesel engine.

- Improve fundamental understanding of combustion instabilities for use in the development of predictive controls and diagnostics.

- Develop and evaluate potential control strategies for enabling and/or expanding HECC operation on a multi-cylinder diesel engine.

\section{Benefits to the Funding DOE Office's Mission}

An improvement in the fuel efficiency of heavy-duty diesel engines is necessary to realize a significant reduction in U.S. energy usage. Low temperature combustion modes such as premixed charge compression ignition (PCCI) are of considerable interest because of reductions in engine-out emissions with no sacrifice in fuel efficiency. The successful widespread implementation of advanced combustion modes such as PCCI is expected to result in improved vehicle efficiency and therefore a reduction in the United States dependence on foreign oil. This is in direct support of the highest priorities of the Office of Energy Efficiency and Renewal Energy.

\section{Technical Discussion of Work Performed by All Parties}

The purpose of this CRADA was to expand the operational range of advanced combustion modes on heavy-duty engines. These combustion modes make use of high levels of dilution to achieve dramatic reductions in NOx and particulate matter (PM) emissions while still maintaining high efficiency. Major challenges include limited operational range due to high pressure rise rates and stability issues. The initial approach was focused on the application of novel analysis and modeling techniques developed from the application of nonlinear dynamics and chaos theory. More specifically, analytical techniques derived from these theories were to be used to detect, characterize, and control the combustion instabilities that 
are responsible for poor combustion performance and corresponding high emissions. Specific steps being used to meet the project objectives include:

- Experimental generation of engine performance and emissions measurements at extreme operating conditions;

- Analysis of the experimental data with nonlinear time series techniques;

- Development of low-order, predictive combustion models; and

- Analytical and experimental implementation of the real-time control strategies based on insights provided by nonlinear dynamics and the combustion models.

The following discussion provides an example of the experiments performed during the course of this CRADA.

Phase 1

The CRADA team defined a series of experiments to be performed at DDC to provide insight into engine response to high dilution operation for several speed/load and air-to-fuel conditions. Data included incylinder pressure from three cylinders as well as standard low-speed measurements of temperatures and pressures. After numerous iterations and data sharing between DDC and ORNL, the team decided to install an engine at ORNL to make best use of available resources. The engine chosen was a prototype DDC Series 60 with a common rail fuel system.

\section{Phase 2}

ORNL staff was trained on the prototype engine at DDC and then the engine was transferred to ORNL. Extensive experiments were performed to determine the operational boundaries of PCCI operation and to characterize the common rail fuel system for enabling these combustion modes. The majority of experiments were performed with a single injection event to keep the parameter space reasonable for the majority of experiments. The frequency and timing of multiple injection events was investigated to a more limited extent in later experiments.

The initial exploratory experiments performed on this engine involved studying the effect of load and EGR on emissions and efficiency. Specifically, the purpose of these experiments was to determine whether high EGR is sufficient to cause a simultaneous reduction in NOx and PM as has been observed on some light-duty diesel engines. An EGR level sweep was performed for three loads and $1500 \mathrm{rpm}$ with all other engine parameters held constant. The results showed a significant decrease in NOx and a significant increase in smoke number with increasing EGR level for all three engine loads. The increase in EGR level also resulted in a decrease in efficiency and a significant increase in CO emissions. An analysis of the in-cylinder pressure data showed an increase in the $10-50 \%$ and $50-90 \%$ burn durations with increasing EGR level and little to no effect on cyclic dispersion, which was within acceptable ranges.

The effects of beginning of injection (BOI) and fuel pressure were investigated at multiple loads for a fixed speed of $1500 \mathrm{rpm}$. EGR rate was held fixed at a slightly elevated level to improve NOx suppression. In general, smoke number decreased and NOx increased with increasing fuel pressure. A simultaneous reduction in NOx and smoke number was observed for later injection timings. This is opposite of the classic NOx-PM tradeoff which is often observed under conventional operating conditions with elevated dilution levels. An analysis of in-cylinder pressure data showed a decrease in the $10-50 \%$ burn duration with decreasing fuel pressure, and the 50-90\% burn duration decreased with retarding injection. All parameters investigated had little to no effect on cyclic dispersion. 
General parameter effects are summarized in Table 1. Note that the effect of each parameter is influenced by a variety of engine conditions including speed and load. For example, the effect of fuel rail pressure on smoke number appears weaker at high loads. Trends summarized in Table 1 are only for the evaluated parameter combinations.

A simultaneous reduction in NOx and PM emissions was observed with retarded (later) injection timings. A simultaneous reduction was not observed for elevated EGR levels for the conditions investigated in this study but may be possible depending on the settings of other operational parameters such as fuel injection rate and timing. Increasing rail pressure appeared to be most effective at reducing PM while maintaining

Table 1: Summary of parameter effects observed in recent experiments.

\begin{tabular}{|l|c|c|c|c|c|}
\hline Parameter & $\begin{array}{c}\text { NOx } \\
(\mathrm{g} / \mathrm{hp}-\mathrm{hr})\end{array}$ & $\begin{array}{c}\text { PM } \\
(\mathrm{g} / \mathrm{hp}-\mathrm{hr})\end{array}$ & $\begin{array}{c}\text { BSFC } \\
(\mathrm{g} / \mathrm{hp}-\mathrm{hr})\end{array}$ & $\begin{array}{c}10-50 \% \mathrm{HR} \\
(\mathrm{deg})\end{array}$ & $\begin{array}{c}50-90 \% \mathrm{HR} \\
(\mathrm{deg})\end{array}$ \\
\hline EGR increase & $\downarrow$ & $\uparrow$ & $\uparrow$ & $\uparrow$ & $\uparrow$ \\
\hline Fuel Pressure increase & $\uparrow$ & $\downarrow$ & - & $\downarrow$ & - \\
\hline BOI retard & $\downarrow$ & $\uparrow \downarrow$ & $\uparrow$ & $-\downarrow$ & $\downarrow$ \\
\hline
\end{tabular}

efficiency, particularly at lower loads. This study indicates simultaneous reductions of NOx and PM emissions (as compared to baseline) are possible with single-injection approaches. More advanced injection strategies involving multiple injections and early injection are expect to provide greater reductions with the ability to maintain efficiency.

\section{Subject Inventions}

No inventions were filed under this CRADA.

\section{Commercialization Possibilities}

This CRADA was important in establishing a strong foundation for further refinement and the eventual introduction of advanced combustion modes in heavy duty engines. Detroit Diesel Corporation will continue to pursue these technologies in combination with Oak Ridge National Laboratory and others through a recent award from the DOE.

\section{Plans for Future Collaborations}

ORNL and DDC plan on continuing collaborations through a new partnership with DOE and the SuperTruck Program, “Systems Level Technology Development and Integration for Efficient Class 8 Trucks”.

\section{Conclusions}

Progress was made to better understand the challenges associated with high dilution operation in heavyduty diesel engines. More specifically, the potential of a flexible prototype fuel system was investigated to understand the opportunities of improved fuel injection control for enabling and expanding advanced combustion operation. This knowledge was used to form the basis of continued collaborations between ORNL and DDC. 